\title{
Contribuciones del feminismo posestructuralista al activismo de las personas con discapacidad en el contexto chileno
}

\author{
Contributions of poststructuralist feminism to the activism of people \\ with disabilities in the Chilean context
}

\begin{abstract}
Resumen
Este artículo tiene el objetivo de analizar la influencia del feminismo posestructuralista en los movimientos de las personas con discapacidad. A través de una metodología hermenéutica interpretativa se analiza cómo las ideas de feministas posestructuralistas que comienzan en la década de los 90' se relacionaron fuertemente con los activismos de la discapacidad desde los 2000 en adelante. Los resultados del análisis revelan que en especial las ideas de Judith Butler, Donna Haraway y P. Beatriz Preciado han influenciado la emergencia y desarrollo de movimientos sociales de la discapacidad bajo conceptos como el conocimiento situado, la resistencia, la somatopolítica, la deconstrucción del género, el orgullo gay, la experimentación del cuerpo, entre otros. Se concluye que existe una relación estrecha entre epistemología feminista posestructuralista y activismo de la discapacidad, constituyendo este último un espacio donde la epistemología se encarna y a la vez, la tensiona y renueva a través la vivencia política.
\end{abstract}

\section{Palabras clave}

Feminismo posestructuralista, disability studies, activismo de la discapacidad, discapacidad, crip.

\begin{abstract}
This article aims to analyze the influence of poststructuralist feminism on the movements of people with disabilities. Through an interpretive hermeneutical methodology, it is analyzed how the ideas of poststructuralist feminists that began in the 1990s were strongly related to disability activism from the 2000s onwards. The results of the analysis reveal that especially the ideas of Judith Butler, Donna Haraway and P. Beatriz Preciado have influenced the emergence and development of social movements of disability under concepts such as situated knowledge, resistance, somatopolitics, the deconstruction of gender, gay pride, body experimentation, among others. It is concluded that there is a close relationship between poststructuralist feminist epistemology and disability activism, the latter constituting a space where epistemology is incarnated and, at the same time, stresses and renews it through political experience.
\end{abstract}

\section{Keywords}

Poststructuralist feminism, disability studies, disability activism, disability, crip.
Michelle Lapierre Acevedo <lapierre.michelle@gmail.com>

Universidad Católica de Temuco. Chile

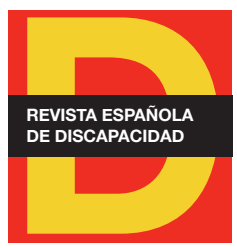

Para citar:

Lapierre, M. (2021). Contribuciones del feminismo posestructuralista al activismo de las personas con discapacidad en el contexto chileno. Revista Española de Discapacidad, 9(2), pp. 81-101.

Doi: <https://doi.org/10.5569/23405104.09.02.05>

Fecha de recepción: 24-04-2021 Fecha de aceptación: 29-11-2021 


\section{Introducción ${ }^{1}$}

Los movimientos de personas con discapacidad son diversos, y sus prácticas son el resultado de epistemologías propias que emergen desde la experiencia y que pueden ser influenciadas por otros movimientos sociales. Estas prácticas pueden enmarcarse en formas asistencialistas de comprender la inclusión, en formas biomédicas centradas en la rehabilitación, o pueden desarrollarse bajo premisas críticas, que cuestionan el abordaje institucional de la discapacidad y profundizan en el análisis del propio concepto.

Los estudios críticos de la discapacidad emergen influenciados por la experiencia de los denominados disability studies. Estos definen la discapacidad como un fenómeno fundamentalmente social, cultural, político, histórico y relacional, y consideran que "identificar a una persona como alguien con discapacidad es un acto ideológico" [traducción propia] (Pfeiffer, 2002, p. 3). La emergencia de este campo ha permitido la investigación y el desarrollo académico de perspectivas diversas de la discapacidad, aunque inicialmente se ha desarrollado en el mundo anglosajón y más tardíamente (aunque de manera rápida y profusa) en Latinoamérica. Así, los estudios en discapacidad se han cruzado con influencias de epistemologías, teorías y paradigmas críticos provenientes de distintos campos de estudio. Los feminismos han sido uno de ellos (Garland-Thomson, 2017), aunque desde diversos tipos y enfoques (Kafer, 2013). Una de las mayores y primeras influencias del feminismo en la discapacidad se ha dado gracias al concepto de interseccionalidad. Este enfoque apareció como concepto a finales de los 80', propuesto por Crenshaw, pero ya venía evidenciándose de forma práctica en el feminismo negro y chicano desde los años 70 (Cubillos, 2015). Esta teoría es una denuncia al feminismo hegemónico o blanco, el cual plantea solo un sujeto del feminismo con identidad común y subordinada a una misma opresión. La teoría de la interseccionalidad permitió integrar la variable género para comprender mejor a las mujeres con discapacidad, no solo como personas, sino como mujeres con características y realidades asociadas a la vivencia de la discapacidad, visibilizando al patriarcado como un elemento crucial para poder entender esa experiencia. Inicialmente, entonces, esta teoría aportó a los estudios sobre mujeres con discapacidad, y con ello sentó las primeras bases para los vínculos que han existido entre feminismo y los estudios sobre discapacidad como campo de investigación.

Posterior a ello, otras corrientes dentro del feminismo han influenciado también a la discapacidad, entre ellas, el feminismo posestructuralista. Este tipo de feminismo se consolida a partir de la tercera ola feminista, que se caracterizó por cuestionarse sobre quién era el sujeto político del feminismo y reconocer al cuerpo femenino como una producción cultural e histórica. Con estos planteamientos, el posestructuralismo, tanto europeo como estadounidense, logró afianzar una relación para desarrollar la idea de este nuevo feminismo (Zambrini, 2014). De ahí en adelante, quedaría un largo camino que recorrer para iniciar un vínculo con las discapacidades que se fortalece en la actualidad. Una de las temáticas más relevantes para el posestructuralismo es el concepto de cuerpo, y sus planteamientos permitieron contribuir al feminismo en general y al feminismo posestructuralista en particular, para avanzar en profundidad en el análisis de este concepto. A partir de ello, creemos que la discapacidad ha encontrado un terreno fértil de la mano de las ideas del feminismo posestructuralista, sobre el cual hacer dialogar sus ideas y experiencias.

De acuerdo a esto, este artículo se levanta sobre el planteamiento de las siguientes interrogantes preliminares ¿Por qué y cómo el feminismo posestructuralista ha influenciado a los estudios sobre discapacidad

1. Agradecimientos: este trabajo ha contado con el apoyo de ANID-PFCHA/Doctorado Nacional/2019-21191201. 
y al movimiento de personas con discapacidad? ¿Cómo ha ocurrido y está ocurriendo esto? ¿Qué otros conceptos e ideas provenientes del feminismo posestructuralista le han sido útiles al estudio de la discapacidad? ¿Cómo estos enfoques teóricos y epistémicos han logrado permear las prácticas de los colectivos de personas con discapacidad? ¿Cómo y cuáles son estas prácticas? ¿Es posible concluir que esta influencia ha contribuido a crear movimientos de personas con discapacidad emancipados?

Este estudio recogerá experiencias activistas de personas con discapacidad en Chile que, debido a su enfoque crítico y feminista, se presumen influenciadas por el feminismo poestructuralista. Se presentarán estas experiencias analizadas e interpretadas desde este enfoque teórico-filosófico, recorriendo conceptos como la teoría crip, la teoría queer, los derechos sexuales y experiencia encarnada que pueden desprenderse de las producciones escritas y visuales que han realizado estos movimientos. Hacia las conclusiones, se tensionarán algunos de los resultados con perspectivas que complejizan y enriquecen el diálogo en torno a los potenciales del feminismo posestructuralista en la discapacidad.

\section{Planteamientos teóricos}

\subsection{Disability studies}

Tal como lo definen sus creadores, este término no solo hace referencia a un campo de estudio académico sino también a un área de actividad política (Davis, 2017). El término hace referencia a "un modelo sociopolítico-cultural de la discapacidad encarnada" (Linton, 1998, p. 526). Este campo de estudios localizó a la discapacidad fuera del ámbito de las ciencias de la salud y lo posicionó en un campo interdisciplinario, fuertemente marcado por las ciencias sociales, cuestionando la medicalización y patologización de la discapacidad. Además, trasladó la discapacidad desde un problema individual hacia un fenómeno colectivo y puso énfasis en la importancia de que las voces de las propias personas con discapacidad tuvieran espacio para la agencia. Y, entre otros aspectos, hizo visible la necesidad y posibilidad de una epistemología de la discapacidad y la inclusión (Linton, 1998).

Así, este campo "sirve no solo para una reconstrucción interpretativa del fenómeno de la discapacidad, sino que también provee de algunas de las líneas operativas a desarrollar para una actuación directa en la ayuda a las personas en situación de discapacidad" (Ferreira, 2008, p. 149). Para el análisis de la discapacidad, los disability studies se basan de forma importante en el posestructuralismo, y en particular en las teorías de Foucault (Davis, 2017; Barton, 2008; Balza, 2011).

Posterior al avance de los disability studies, aparecieron diversas líneas dentro de este mismo campo, entre las cuales emergieron los estudios feministas de la discapacidad (feminist disability studies). Este campo, según Garland-Thomson (2005) quiere:

“(...) remover los agotados estereotipos sobre las personas con discapacidad. Busca desafiar nuestras suposiciones dominantes sobre vivir con una discapacidad. Sitúa la experiencia de la discapacidad en el contexto de los derechos y exclusiones. Aspira a recuperar voces descartadas y experiencias tergiversadas. Nos ayuda a comprender la intrincada relación entre cuerpos y seres. llumina los procesos sociales de formación de identidad. Su objetivo es desnaturalizar la discapacidad. En resumen, los estudios feministas sobre discapacidad vuelven a imaginar la discapacidad" [traducción propia] (p. 1557). 
De acuerdo a lo anterior, esta línea dentro de los disability studies no se centra solamente en el estudio de las mujeres con discapacidad, sino en el estudio de la discapacidad bajo el prisma de los estudios de género y feminismos (Balza, 2011).

En lberoamérica también emergen, y con algunas tensiones, en relación con las propuestas originales del Norte Global. López-Radrigán plantea que estas surgen "de la tensión epistemológica y ontológica en torno a la cualidad prelingüística de los cuerpos, entendidos como experiencias encarnadas y territorializadas de discursos performativos y materialidades, donde se intersectan fronteras binarias de la matriz moderno/ colonial" (2020, p. 97).

Posterior a los disability studies, e influenciados por estos, nacen los estudios críticos de la discapacidad, como un campo desde el cual diversas teorías críticas conversan en relación a la discapacidad como objeto de estudio, los que se han posicionado con fuerza en lugares como Latinoamérica, en diálogo con las perspectivas críticas latinoamericanas (Yarza et al., 2019).

\subsection{Activismo de la discapacidad}

El activismo de la discapacidad nace al alero de otros activismos sociales, en particular con los movimientos por los derechos de personas afrodescendientes y migrantes en los Estados Unidos desde los años 60 (Blanco, 1999). Aunque algo más lentamente que otros grupos minorizados, las personas con discapacidad han ido colectivizándose y manifestando sus derechos en distintos sentidos. Los primeros activismos tenían relación con visibilizar la discriminación, estigmatización y exclusión social de las cuales eran sujetos, y así nacieron convenciones internacionales relevantes utilizadas hasta hoy en el marco de la lucha por los derechos humanos, como la Convención sobre los derechos de las personas con discapacidad. Luego, estos movimientos se volcaron a la demanda de protección social y acceso a servicios de salud y rehabilitación, pues se presentaban carencias importantes en términos de redistribución social y equidad (Águila, 2007). En este periodo histórico, y a la luz de estos hechos, nace en Estados Unidos e Inglaterra el modelo social de la discapacidad, que propuso ser una contrapropuesta a los modelos rehabilitadores que se centraban en las deficiencias de las personas. Este modelo se extendió rápidamente por todo el mundo y tiene gran vigencia en la actualidad. Su aparición resultó en una reforma de mucha relevancia para los movimientos de personas con discapacidad y la posterior aparición de los disability studies (Shakespeare, 2017). Palacios, investigadora latinoamericana estudiosa de este modelo, lo define de la siguiente forma:

"Los presupuestos fundamentales del modelo social son dos. En primer lugar, se alega que las causas que originan la discapacidad no son ni religiosas ni científicas, sino sociales o al menos, preponderantemente sociales. (...). En cuanto al segundo presupuesto (...) partiendo de la premisa de que toda vida humana es igualmente digna, desde el modelo social se sostiene que lo que puedan aportar a la sociedad las personas con discapacidad se encuentra íntimamente relacionado con la inclusión y la aceptación de la diferencia” (Palacios, 2008, pp. 103-104).

Posteriormente, estos movimientos demandaron la construcción conjunta de políticas públicas, en un slogan de alcance mundial que citaba "nada para nosotros, sin nosotros", donde elementos como la experiencia personal y la co-construcción con el personal social y de salud fueron lo más relevante (Pérez y Chhabra, 2019). Luego de esto, y con la intención de hacer confluir parte de las ideas renovadas que proponía el modelo social con la experiencia que ya traía el modelo rehabilitador, la Organización Mundial de la Salud levanta la propuesta del enfoque/modelo biopsicosocial como abordaje de la discapacidad (Fuentes et al., 2021). Este 
ha tenido una amplia recepción en el mundo académico, institucional y de organizaciones de la sociedad civil, especialmente para quienes conceptualizan la discapacidad desde el campo de la salud, pero a través de una perspectiva compleja del concepto. Es aplicado sobre todo en los espacios institucionales para la creación de políticas públicas sobre discapacidad y su aparición ha resultado de relevancia para muchas personas con discapacidad que efectivamente requieren de la red sanitaria para alcanzar derechos y participación.

Actualmente, una buena parte de los movimientos de personas con discapacidad se han vuelto más politizados y ha emergido un cuestionamiento a la noción de cuerpo discapacitado, se ha retomado la idea de derechos desde una visión más amplia que los derechos básicos sociales y culturales, dando paso a las intersecciones con la raza, la migración y el género, y donde la idea de emancipación y liberación ha sido central (Barton, 2008). Los movimientos sociales de personas con discapacidad asociadas a las artes han sido también muy recurrentes en los últimos años y han ocupado espacios públicos de alta connotación con un fin transgresor y político (Miranda, 2020).

Parte de los activismos han encontrado en el concepto de capacitismo un soporte teórico-ideológico desde el cual comprender la situación de la discapacidad en las sociedades contemporáneas y podemos situar su origen en los movimientos anglosajones de personas con discapacidad (Wolbring y Guzmán, 2016). Existen diversas definiciones de este concepto, pero aquí recordaremos la definición de Campbell (2001) que señala que el capacitismo es

"Una red de creencias, procesos y prácticas que produce un tipo particular de tipo de yo y de cuerpo (el estándar corpóreo) que se proyecta como perfecto, típico de la especie y, por tanto, esencial y plenamente humano. La discapacidad se presenta entonces como un estado disminuido del ser humano" [traducción propia] (p. 44).

En Iberoamérica ha sido desarrollado especialmente por Toboso (2017) en España y Mello (2014), con importantes acercamientos a los activismos críticos. En particular esta última autora lo ha hecho desde los activismos feministas de la discapacidad.

A nivel mundial, y desde una perspectiva histórica, podemos situar a Jenny Morris como una de las pioneras en posicionar al feminismo dentro del activismo de la discapacidad (Pino y Rodríguez, 2017), pues ella relevó la ausencia de la voz de las mujeres y de la voz del feminismo en estos movimientos sociales, y destacó que el concepto de cuerpo utilizado en el modelo social de discapacidad tenía severas limitaciones. Hoy es posible hablar de un movimiento de mujeres con discapacidad a nivel internacional, cuyas prácticas son:

"Luchas por la erradicación de la violencia y los abusos, por la defensa de su autonomía moral en temas tan personales como las decisiones relativas a la maternidad, así como por la eliminación de las barreras discapacitantes de nuestras sociedades para el acceso a ámbitos básicos como la educación, el empleo o la atención sanitaria, entre otros aspectos, existe también una dimensión proactiva vinculadas a reivindicaciones de más amplio calado" (Arenas, 2009, p. 65).

\subsection{Feminismo posestructuralista}

Hoy existe consenso respecto a hablar de feminismos en plural, y no de "el" feminismo como una entidad teórica única (Barrera et al., 2010; Barreto, 2015). Dentro de los diversos feminismos, el posestructuralista es aquel que ha abrazado algunas de las ideas del posestructuralismo, y en especial aquellas bajo la influencia de Foucault, Deleuze y Derrida, tales como las relaciones de poder, la biopolítica y el énfasis en el potencial 
del lenguaje y el discurso, para vincularlas con elementos centrales del feminismo y así obtener ideas, creaciones, conceptualizaciones y nuevos posicionamientos epistémicos sobre los cuales comprender el género (Urra, 2007; Zambrini, 2014; Alcoff, 1988). El posestructuralismo puede definirse como "uno de los discursos académicos postmodernistas, que presta atención al lenguaje, el poder, el deseo y la representación como categorías discursivas" (Pinar et al., 1995, como se citó en Rifa, 2003, p. 71). Si bien no existe una definición única sobre el feminismo posestructuralista, los autores coinciden en que elementos como la identidad y la diferencia, presentes y centrales en otros feminismos, son criticados desde esta corriente (Scott, 1988; Butler, 2007), así "el feminismo posestructuralista defiende la estrategia de la deconstrucción de nuestras identidades para tratar de escapar de la petrificación de las mismas" (Cano, 2017, p. 46), por lo tanto este feminismo rechaza la categorización de la mujer y del género, para dar paso a una subjetividad más compleja (Alcoff, 1988), que no tenga como consecuencia identidades totalizantes, que promuevan mayormente la exclusión.

El posestructuralismo también ha enfatizado en el conocimiento como elemento para la transformación histórica y social de los regímenes de poder. Este elemento está presente en el feminismo posestructuralista, aplicado a las relaciones de género y al poder en un contexto patriarcal. Desde aquí, aparece además el concepto de resistencia, el cual estaría en oposición al ejercicio del poder, generando espacio para lograr el cambio (Doering, 1992).

Algunas de las feministas más relevantes que basan o incorporan en su pensamiento los enfoques posestructuralistas son: Luce Irigaray, Hélène Cixous, Judith Butler, Donna Haraway, Rosi Braidotti y Paul B. Preciado.

Existen muchos conceptos que están relacionados con el feminismo posestructuralista y que han sido fundamentales para inspirar, articular y estructurar algunos de los activismos más actuales en la discapacidad. Estos conceptos, entre otros son: el conocimiento situado, la deconstrucción del género y teoría queer, el orgullo gay, la experimentación del cuerpo, la ciencia ficción feminista utópica, la somatopolítica, el posporno, entre otros. Para objetivo de este análisis nos centraremos solo en algunos de ellos, específicamente: el conocimiento situado, la deconstrucción del género y teoría queer, y el posporno.

En relación al conocimiento situado, si bien la creación del concepto como tal emergió en los trabajos de Haraway y Harding, es justo aclarar que su aparición y aplicación es previa y formó parte del proyecto feminista de otras mujeres de la época (Cruz et al., 2012). Haraway escribió la primera vez sobre este concepto en alusión a la objetividad e imparcialidad tan deseadas en la ciencia, "yo quisiera una doctrina de la objetividad encarnada que acomode proyectos de ciencia feminista paradójicos y críticos: la objetividad feminista significa, sencillamente, conocimientos situados" (Haraway, 1991, p. 324). Su propuesta originó una oleada de usos y reinterpretaciones y se mantiene plenamente vigente, a pesar de sus 30 años de existencia (Guzmán-Cáceres, 2015). Así,

"El concepto de conocimiento situado ha sido empleado a menudo para justificar la autoridad que, por lo menos en sus propios términos, tendrían sistemas de pensamiento y formas de conocimiento diferentes de aquellas que han pretendido edificar visiones universales desde el no-lugar de la objetividad científica" (Piazzini, 2014, p. 12).

De esta manera, observaremos más adelante cómo los activismos de la discapacidad han revalorado su propia experiencia histórica, su cuerpo como encarnación de la vivencia de la discapacidad, y su voz en primera persona como autoridad sobre la materia.

Sobre la deconstrucción del género y la teoría queer, si bien sabemos que Butler es quizás la mayor teórica que ha tenido el feminismo en el cuestionamiento del género y construir una teoría de ello, ya muchos años 
antes Simón de Beauvoir nos había entregado su famosa frase "no se nace mujer, se llega a serlo" y con ello sentó las primeras bases para lo que hoy llamamos la deconstrucción del género (García, 2012). Butler propone que el cuerpo pierda su condición de ser objeto de la ciencia, para trasladarse al campo político, implantando la duda en la sociedad acerca de las "verdades" sobre el género que se asumían hasta entonces. La autora, sobre la visión posmoderna y posestructuralista asociada al género menciona que

"No hay una ontología de género sobre la que podamos elaborar una política, porque las ontologías de género siempre funcionan dentro de contextos políticos de terminados como preceptos normativos: deciden qué se puede considerar sexo inteligible, usan y refuerzan las limitaciones reproductivas sobre la sexualidad, determinan los requisitos preceptivos mediante los cuales los cuerpos sexuados o con género llegan a la inteligibilidad cultural" (Butler, 2007, pp. 287-288).

Estos enfoques de deconstrucción del género han sido fundamentales para la posterior consolidación de la teoría queer. En inglés, la palabra queer ha sido utilizada de forma peyorativa para referirse a las personas gay, y como verbo se traduce como desestabilizar o perturbar. Los activistas de la disidencia sexual estadounidenses revirtieron el sentido de esta palabra, y crearon a partir de ello una epistemología subversiva y transgresora (Fonseca y Quintero, 2009), que cuestiona la institucionalidad, la heteronormatividad, y la práctica sexual culturalmente aceptada. Si bien el concepto queer es previo a gender trouble de Judith Butler, este último fue de enorme influencia para su transformación en una teoría y posterior aplicación en diversos ámbitos de cuestionamiento a la normatividad, lo que toma especial sentido para la idea de cuestionar las identidades. "Para Butler, cualquier categoría de identidad controla el erotismo, describe, autoriza $\mathrm{y}$, en mucho menor medida, libera. La teoría no debería entenderse en el simple sentido de contemplación desinteresada, sino que es totalmente política" (Fonseca y Quintero, 2009, p. 48).

El concepto de posporno es más actual que los anteriores. Una de las feministas más importantes en el planteamiento del posporno en tanto teoría y activismo es Paul B. Preciado, sin embargo, este movimiento socialartístico y posteriormente enfoque teórico, nace de la mano de una estrella porno estadounidense, Annie Sprinkle y la socióloga posestructuralista Marie-Hélène Bourcier. Se define como un cuestionamiento a la industria pornográfica, tanto por su relación con el mercado y el capitalismo, como por su enfoque patriarcal en los contenidos pornográficos. Smiraglia considera que el feminismo fue un movimiento pionero en leer críticamente la práctica y experiencia de la pornografía, así como sus imaginarios culturales. Sobre esto refiere que:

"No obstante, frente a ese diagnóstico inicial, dos respuestas en contraposición se plantearon como estrategia a seguir: por un lado, un feminismo abolicionista que busca proteger a las mujeres de esas imágenes -violentas, discriminatorias- a través de su censura, y por el otro, un feminismo denominado generalmente pro-sexo que plantea, en cambio, la disputa de ese espacio de la representación sexual” (2012, p. 2).

El feminismo posestructuralista ha optado, en esta disputa, por un feminismo pro-sexo que promueve acciones sexuales reivindicativas. Este feminismo es "un nuevo feminismo anticensura que entiende el cuerpo, la sexualidad y la pornografía como espacios posibles de resignificación y de empoderamiento político para las mujeres y las minorías sexuales" (Rodríguez, 2013, p. 258).

Dentro de estos espacios se encuentra el posporno. Siguiendo las ideas de Butler y de la teoría queer, este se posiciona desde la construcción social del género y la deconstrucción del mismo. Así,

"La relación entre sexualidad y pornografía no es del orden de la representación, sino de la producción (...) la pregunta no es si es posible un porno femenino, sino ¿cómo modificar jerarquías visuales que nos han constituido 
como sujetos? ¿Cómo desplazar los códigos visuales que históricamente han servido para designar lo normal o lo abyecto?" (Preciado, 2015, párr. 5).

El posporno puede utilizar distintas artes, como el video, la pintura, la fotografía, etc. para tensionar los imaginarios pornográficos hegemónicos y mostrar la deconstrucción del género y el cuerpo, lejos de la industria pornográfica global (Egaña, 2017).

\section{Método}

El método mediante el cual se realizó el estudio corresponde al análisis hermenéutico interpretativo, ubicando a este en el paradigma cualitativo e interpretativo-comprensivo de la investigación. La hermenéutica propone a la interpretación de los textos como una forma de comprender los fenómenos sociales (Gadamer, 1991). De acuerdo a esto, "el objeto revelado del análisis gadameriano es más bien el de sacar a la luz las estructuras transcendentales del comprender, o sea, clarificar los modos de ser, en que se concreta el fenómeno interpretativo" (Arráez et al., 2006, pp. 177-178).

Si bien la hermenéutica es una disciplina antigua, el propio Gadamer (1991) ha señalado que no puede aplicarse bajo metodologías estructuradas, y que la interpretación debe estar ligada permanentemente al contexto sociocultural en que se dan los fenómenos que señalan los textos y la forma en que están escritos.

En relación a esto último, las formas de escritura que son analizadas en esta investigación no obedecen al formato de texto clásico en todos los casos, sino que integran además textos en formatos más usadas por los movimientos sociales, tales como columnas, boletines, entrevistas, publicaciones de redes sociales, etc. Sobre esto, Arráez et al. (2006) plantean que "las novedosas formas de interpretación son fundamentales para propiciar espacios de diálogo" (p. 178).

Para seleccionar los textos, se realizó una búsqueda en Internet y redes sociales con el propósito de identificar colectivos, organizaciones y líderes dentro del movimiento de personas con discapacidad en Chile y se seleccionaron aquellos que, de acuerdo al marco teórico, presentaban prácticas posibles de ser interpretadas y analizadas desde el feminismo posestructuralista. Se recogieron algunas prácticas activistas de acuerdo a su nivel de significado y riqueza para la reflexión interpretativa.

De acuerdo al análisis hermenéutico, el texto tiene un propósito propio y un contexto de referencia desde el cual surge. Estos representan puntos de partida para la interpretación, pero del análisis se desprende su verdadero sentido ontológico, al vincular lo histórico y cultural. El análisis hermenéutico sostiene que los textos son polisémicos y, por lo tanto, pueden ser interpretados desde posicionamientos teóricos diversos (Gadamer, 1991). Para este análisis de los textos se interpretaron sus elementos ideológicos, narrativos, culturales y epistemológicos, pues estos permiten generar un vínculo con el feminismo posestructuralista como enfoque teórico-conceptual de la investigadora. Y se ha utilizado la comparación, como propone el análisis hermenéutico, para comprender mejor las prácticas activistas chilenas. Para esto se ha aludido a algunas de las prácticas y activismos más destacados en otras partes del mundo.

Esta interpretación plantea el desafío del círculo hermenéutico en el que, si bien se toman los textos producidos por lo sujetos, en este caso los colectivos activistas, esto 
"No implica solo quedarse con el texto y en él; sino que es una interpretación que requiere de la voluntad del sujeto que conoce para trascender las "fronteras" del texto a interpretar. En este sentido, se debe entender el proceso de análisis hermenéutico en permanente apertura, producto de la actividad re-interpretativa de la que es fruto. Así, dicha re-interpretación no es pura referencia al texto, sino que a la interpretación de la interpretación que hace el autor respecto a un fenómeno determinado" (Cárcamo, 2005, p. 211).

Así, la interpretación que se ha hecho obedece a la diversidad propia de los textos escogidos, a la diversidad del feminismo posestructuralista como horizonte teórico-filosófico desde el cual realizar la interpretación y al contexto sociopolítico en movimiento en que estos activismos se desarrollan en Chile.

\section{Análisis}

Dentro de los activismos de la discapacidad existen variadas experiencias y movimientos sociales que pueden leerse como influidos por el feminismo posestructuralista, ya que sus prácticas se expresan en diálogo con algunos de los aspectos que aquí hemos relacionado con el feminismo posestructuralista, tales como la sexualidad disidente y abierta, la performatividad, movimientos que se ven representados por el disability pride, colectivos que generan un discurso a favor del movimiento crip y la visibilización de la experiencia encarnada de la discapacidad a través de la literatura. Es importante mencionar que existen numerosos movimientos de personas con discapacidad incipientes y consolidados alrededor del mundo, con otras experiencias de activismos que también pueden ser analizados desde esta perspectiva. Se relacionarán estos movimientos globales con algunos activismos locales a nivel latinoamericano y especialmente chileno, con el fin de poder situar estas experiencias desde la realidad latinoamericana.

\subsection{Movimientos que promueven la sexualidad en la discapacidad}

Quizás sea el documental español Yes, We Fuck! el que impulsó la necesidad de promover la temática de la sexualidad en personas con discapacidad desde una perspectiva crítica y posestructuralista, si bien ya venía siendo trabajada por distintos colectivos, especialmente el Movimiento de Vida Independiente (España), de donde emerge también uno de sus directores, Antonio Centeno. Estrenado en el X Porn Film Festival de Berlín, en 2015. El documental en sí es un activismo político-artístico en el campo del cine, de la mano de un director en situación de discapacidad física, sin embargo, las seis historias de vida que en él se relatan nos revelan los activismos en la sexualidad y la pospornografía en los movimientos de personas con discapacidad en España. En dicho festival, Yes, We Fuck! fue presentado como:

"Un documental que forma parte de la línea del festival "Sexo y discapacidad" y aborda no solo la cuestión de sexualidad de personas con diversas discapacidades, sino también feminismo, trans-feminismo, LGBT, queer, intersexual, activismo gordo y otros. En 6 episodios veremos a las personas hablar sobre y realizar actos explícitos de su sexualidad, en todas las formas de habilidad física2" (10 Porn Film Festival Berlin, 2015, p. 30).

El nombre del documental alude a la famosa frase de la campaña presidencial de Obama, Yes, we can!, y se relaciona también según su director con que "somos el único colectivo al que se describe por lo que no 
puede hacer" (Gallego, 2015, párr. 2) y muestra la historia de personas con discapacidad y su vivencia de la sexualidad, en relación a la vida en pareja, la asistencia sexual y la prostitución (Zurro, 2015). Su exhibición reveló y a la vez consolidó activismos relacionados con el consumo de la prostitución como una opción para personas con discapacidad, la exploración sexual colectiva del cuerpo en personas ciegas, y el uso de asistentes sexuales para lograr el autoerotismo en personas con movilidad reducida (Centeno y de la Morena, 2015). Una de las motivaciones para la elaboración de este documental, es que "los millones de páginas pornográficas no muestran a personas discapacitadas. $O$ se les considera ángeles, asexuados, 0 aparecemos como fetiches, no como sujetos que vivamos nuestra sexualidad" (Zurro, 2015, párr. 7).

La asistencia sexual a las personas con discapacidad que aparece en el documental reveló un activismo incipiente en España creado por alianzas entre personas en situación de discapacidad y profesionales del área de la rehabilitación y la sexualidad, y que posterior al film se extendió como una opción demandada por las personas con discapacidad en distintas partes del mundo, ampliándose también en España, a cargo de diversas ONG (Torrico, 2016).

En Chile han nacido iniciativas dirigidas a la asistencia sexual lideradas por personas con discapacidad, y aunque avanzan lentamente en su oficialización, poco a poco han logrado instalar la temática, con apoyo de organizaciones argentinas que ya han echado a andar estas prácticas activistas, lideradas por Silvina Peirano. El colectivo Diversidad Funcional Chile y la organización Odisex (Observatorio de Derechos Sexuales y Reproductivos de las Personas con Discapacidad) se encuentran avanzando en estas iniciativas y existe la necesidad de crear un Foro de Vida Independiente Chile, a la usanza del mismo en Cataluña, que ha potenciado estos activismos de sexualidad y posporno (Zunino, 2017). Paula Bravo, directora de Odisex plantea sobre la asistencia sexual:

"Me parece que es una excelente opción, pero en Chile estamos muy lejos de alcanzarla. Primero hay que reconocer y promover la naturalización de la sexualidad de las personas con discapacidad y mientras eso no ocurra los asistentes sexuales van a ser considerados como una idea exótica, de personas locas. Acá no se considera la intimidad como necesaria para una vida digna de alguien con discapacidad. En Odisex hay profesionales que se están capacitando y tomaron cursos sobre esto fuera de Chile, sin embargo, sabemos que va a ser muy complejo instalarlo (Ellies, 2016, párr. 9).

En su relato podemos interpretar una necesidad de cambio social para hacer posible la incorporación de este tipo de prácticas, y no al revés. Plantea un cambio progresivo con el fin de que la asistencia sexual sea reconocida y no exotizada desde lo porno.

Preciado, sobre el posporno como teoría, refiere

"La nouvelle vague post-porno, transfeminista y tullido hecho sobre todo con video (Eric Pussyboy, Abigail Gnash, Lucie Blush, Courtney Trouble, Virginie Despentes, Gaspar Noe, Post-Op, Del LaGrace Volcano, YesWeFuck...) no busca representar la verdad del sexo sino cuestionar los límites culturales que separan la representación pornográfica y no pornográfica, así como los códigos visuales que determinan la normalidad o la patología de un cuerpo o de una práctica" (2015, párr. 3).

Yes, We Fuck! se plantea como una contra-propuesta no solo a la pornografía tradicional sino a pensar a las personas con discapacidad como seres diversexuales visibles, explícitos y transgresores, "entendiendo que -en palabras de Preciado- el antídoto frente a la pornografía hegemónica no es la censura, sino la producción y circulación de propuestas alternativas" (Smiraglia, 2012, p. 4). Vemos que este documental, 
entendido como práctica política, no tiene necesariamente ni únicamente el interés de excitar a la audiencia con las muestras explícitas de sexo que se observan en el recorrido de estas seis historias, como pretende la pornografía tradicional, debido a que

"Lxs activistas posporno generan una apuesta estética y política: no se trata solo de crear representaciones alternativas de la sexualidad, sino de indagar nuevas posibilidades artísticas; procurar no solo -o más - que la excitación del público, en pos de un goce estético" (Peralta, 2017, p. 231).

\subsection{Teoría y movimiento crip}

Al igual que queer, crip en inglés es una palabra peyorativa con la que se ha denominado a las personas con discapacidad (McRuer, 2021). Se traduce al español como "tullido" y representa una historia de exclusión de esta población. Tal cual lo hicieran los activismos de la disidencia sexual, las personas con discapacidad han reivindicado esta palabra y la han transformado en un campo de movimiento social y posteriormente se ha teorizado para acompañar una epistemología de esta resistencia y disidencia del capacitismo (Maldonado, 2020; Mareño, 2021; García-Santesmases, 2017; McRuer, 2021). El creador de la teoría, McRuer, menciona que este concepto se opone tanto al modelo médico como al modelo social de la discapacidad, ofreciendo un concepto "centrado en el exceso, el desafío y la transgresión extravagante: crip ofrece un modelo de discapacidad que es culturalmente más generativo (y políticamente radical) que un modelo social que es solamente, más o menos, reformista (y no revolucionario)" (Moscoso y Arnau, 2016, p. 138). Es interesante como el activismo crip no solamente se ha influenciado de la teoría queer, sino que además se posiciona como un influyente en el sentido contrario, esto es, desarrollar un concepto que a su vez sea capaz de impactar a las disidencias sexuales que se enmarcan dentro de lo queer. Un ejemplo es la relación entre lo crip y la propuesta cyborg donde ese vínculo ha permitido también releer este concepto de Haraway (Kafer, 2013). Para García-Santesmases “los feminismos, la teoría queer y la teoría crip permiten desnaturalizar categorías de normativización corporal (...) e identificarlas dentro de un sistema de regulación corporal: el heteropatriarcado y el capacitismo" (2017, p. 1). A esto se le ha denominado también "alianza tullido-transfeminista" y es un área en la que Paul B. Preciado ha demostrado gran interés, relacionandola con el concepto posestructuralista de somatopolítica (Universidad Internacional de Andalucía, 2011).

El activismo crip ha desarrollado un realce de las condiciones físicas, mentales o sensoriales que se catalogan por la ciencia como "anormalidades" o "deficiencias", para evidenciar no solo la aceptación de estas, sino celebrar su existencia, su diversidad y provocar a la ciudadanía a través de actos performativos, especialmente usados por artistas con discapacidad. García-Santesmases y Arenas en su investigación señalan

"La confluencia de estas circunstancias ha permitido a algunos artistas discapacitados (...) crear espectáculos que emplean nuevos lenguajes, en los que se sienten orgullosos de poner en escena lo que antes ocultaban, adoptando un discurso más cercano al de la cultura de la discapacidad y/o a las actitudes crip" [traducción propia] (2017, p. 349).

En estos planteamientos encontramos premisas de lo queer, puesto que "la teoría queer intenta cambiar el sentido de la injuria para convertirla en un motivo de estudio, e incluso de orgullo. Así, ser diferente se toma como una categoría de análisis para denunciar los abusos que se presentan desde la misma ciencia" (Fonseca y Quintero, 2009, p. 44), poniendo énfasis en lo periférico como espacio de reivindicación. 
La teoría crip ha desarrollado el concepto de able-bodidness, inspirado en el concepto de "heterosexualidad obligatoria" acuñado por Rich y trabajado también por Butler. Este concepto podría traducirse al español como "capacidad corporal obligatoria" y busca relevar que la existencia de una "no discapacidad" no es una característica neutral del ser ni una elección de la persona, sino algo que el sistema hace parecer deseable y obligatorio (Moscoso y Arnau, 2016; McRuer, 2018). Esta teoría demuestra cómo es posible subvertir estas lógicas capitalistas y patriarcales desde una acción y práctica performativa, tal como lo ha venido haciendo el colectivo de personas queer, tomando a la discapacidad como una experiencia encarnada (García-Santesmases, 2017).

Activismos relevantes han aparecido alrededor del mundo a partir de la emergencia de la teoría crip. Uno de estos ejemplos lo constituye la líder activista Nomy Lamm, quien se define a sí misma como algo que podría traducirse como "gordajudíatullidacoñobollera" (Proyecto Kahlo, 2014), mostrando la interseccionalidad de sus diversidades y donde lo crip se muestra como parte esencial de su performatividad.

En Chile existe el colectivo de jóvenes mujeres con trastornos del espectro autista (TEA) Ilamado AsperGirls, en el cual es posible observar elementos de la teoría crip en su constitución. A través de un activismo principalmente en redes sociales, estas jóvenes desarrollan memes donde performatizan las "deficiencias" sociales y de comunicación propias de las personas con TEA a través de sus escritos en redes sociales, integrando elementos de humor en sus espacios de reivindicación, siempre desde una perspectiva feminista y de género. Este colectivo se encarga de realizar educación desde una mirada que podemos definir como crip, de la visibilización de la discapacidad y de participación ciudadana en materias de discusión nacional, donde la voz de las personas con discapacidad esté presente, como ha sido recientemente el caso del estallido social del 18 de octubre en Chile y la pandemia de Covid-19.

\subsection{Disability Pride}

La primera Disability Pride Parade fue realizada en Boston, en el año 1990, y se inspiró en el Black Parade y el LGBT Parade, ambos nacidos también en los Estados Unidos. La misión de Disability Pride Parade en la actualidad, es

"Cambiar la forma en que la gente piensa y define la discapacidad, romper y acabar con la vergüenza internalizada entre las personas con discapacidad, y promover la creencia en la sociedad de que la discapacidad es una parte natural y hermosa de la diversidad humana, de la que las personas que viven con discapacidad pueden enorgullecerse" [traducción propia] (Disability Pride Parade Association, párr. 1).

Esta práctica emerge bajo el concepto del "orgullo de la discapacidad", como ha sido traducido al español por algunos países, y nos sugieren la performatividad y el orgullo por la diferencia que nos plantea la teoría queer y los feminismos posestructuralistas. Quienes desarrollan prácticas o investigaciones en esta línea han criticado tanto el modelo médico como el modelo social de la discapacidad, debido a que estos no son capaces de cuestionar el concepto de discapacidad ni celebrar sus diversidades y diferencias, mostrando un interés por la normatividad en sus intentos de reparación e inclusión. Desde esta perspectiva, la discapacidad aparece como algo identitario (Hopson, 2019; Bogart y Nario-Redmond, 2019).

El concepto de "orgullo" se ha planteado como una contraposición a la opresión (Ferrante, 2014), evidenciando una práctica activista de resistencia y una epistemología situada al plantear una nueva comprensión 
de la discapacidad desde un enfoque de resignificación. Por otra parte, este enfoque ha planteado el activismo del orgullo como un opuesto a las prácticas institucionales y estatales de caridad, primando un enfoque de derechos y de relación entre diversos activismos sociales de personas en situación de desventaja social (Pérez y Chhabra, 2019).

Adicionalmente, en los últimos años han aparecido colectivos que se posicionan desde el orgullo de la discapacidad en vínculo con el orgullo gay o LGBTIQ+, con el objetivo de contribuir a que las personas con discapacidad que se definen dentro de una disidencia sexual sean capaces de encarnar ambas experiencias desde una práctica de orgullo de la diversidad. En España el colectivo Diversxs trabaja en este desafío, tanto con personas con discapacidad física como intelectual o mental, acompañado de vivencias sexuales en el abanico de las disidencias. En Chile, Odisex ha planteado esta temática y ha llevado la popular frase de "estar dentro del closet" a encontrarse en una "cruel prisión heterosocial" en el caso de las personas con discapacidad no heterosexuales. Este colectivo ha desarrollado espacios educativos y de apoyo a las personas con discapacidad en estas materias, sin embargo, aún queda un largo camino para consolidar estas prácticas. De acuerdo con la premisa del Orgullo Gay, su presidenta plantea que "la diversidad, en toda su máxima extensión es un maravilloso carnaval. Y de todos quienes creemos en ella, depende que no siga opacando su bello rostro luminoso con el macabro antifaz de los prejuicios, del rechazo y la discriminación" (Bravo, 2016, párr. 13).

En Latinoamérica desde hace varios años se ha desarrollado la Marcha del Orgullo Loco, la cual posiciona el orgullo de la discapacidad en las personas con discapacidad psicosocial, desde un enfoque anticuerdista. Recientemente se ha organizado la $6^{a}$ Marcha por el Orgullo Loco en Chile, liderada por los colectivos Locos por nuestros derechos y Autogestión Libre-Mente, cuyo texto de invitación en post de Facebook señala

"Por sexto año consecutivo posicionamos el Orgullo Loco en Chile, marchando por las calles de la capital Santiaguina, defendiendo la locura, denunciando la violación de nuestros derechos y ejerciendo la expresión de ser Libres de mentes (...) Salgamos a las calles con la locura por delante porque por más que busquen callarnos nosotrxs seguiremos resistiendo y seguiremos luchando ¡Lxs locxs no nos rendimos y somxs la revolución!" (Autogestión Libre-Mente, 2020).

Podemos interpretar que existen elementos culturalmente identitarios, que se utilizan las denominaciones lingüísticas en español que históricamente han denigrado a la discapacidad psicosocial en un sentido reivindicativo y la manifestación de estos elementos en los espacios públicos.

\subsection{Visibilización de la experiencia encarnada de la discapacidad a través de la literatura}

El conocimiento situado es quizás uno de los enfoques más populares del feminismo, y su uso se ha extendido más allá del posestructuralismo. Como se ha mencionado inicialmente, este concepto nos ha permitido reivindicar la experiencia de las personas con discapacidad como un saber encarnado, una epistemología situada y ontología de la resistencia. Este concepto ha permitido la aparición de colectivos de personas con discapacidad que se sitúan desde la experiencia personal y desde el discurso en primera persona, poniendo estos en un nivel jerárquico igual o mayor al del experto teórico académico, demandando y exigiendo su lugar y voz respecto al tema. Para algunas mujeres feministas con discapacidad, la teoría de la interseccionalidad si bien colaboró en visibilizar una realidad, también contribuyó a situarlas desde una doble desventaja o exclusión, perpetuando un imaginario social de experiencia de víctima por sobre una de 
resistencia, cuando numerosos movimientos de personas y mujeres con discapacidad justamente pretendían relevar su resistencia como una práctica emancipadora (Morris, 1996).

Al alero de ese tipo de reflexiones, nacieron movimientos de personas y mujeres con discapacidad que desearon contar su historia desde la voz en primera persona y dar visibilidad al movimiento de personas con discapacidad a través de la literatura. Así, vemos elementos posestructuralistas de este tipo de feminismo, que relevan la literatura y el lenguaje como aspectos esenciales para construir la realidad (Urra, 2007; Rifa, 2003).

A partir de esto, uno de los primeros esfuerzos por reunir relatos en primera persona, desde una voz en el campo de la resistencia, la lucha y la transformación social, fue hecho por Jenny Morris (1996). En su trabajo Encuentros con desconocidas es posible observar una gama de mujeres con discapacidad y sus experiencias encarnadas en un amplio abanico de realidades, diversidades, resistencias y re-existencias. Otras experiencias interesantes han provenido más recientemente de la mano del Disability Visibility Project, el cual se encarga de hacer visibles las historias de personas con discapacidad contadas por su propia voz y difundirlas a través de diversos formatos, generando un círculo de historias. En un continuo esfuerzo de recopilar esas historias, dos libros han nacido de este proyecto liderado por Alice Wong, mujer con discapacidad asiamericana, titulados Resistance \& Hope. Crip wisdom for the people (Wong, 2018) y Disability visibility (Wong, 2020). En Chile, recientemente las jóvenes de AsperGirls han convocado una recopilación de relatos en primera persona de mujeres y no binaries en el espectro autista denominada Experiencias en el mundo educativo (Colectivo AsperGirls Chile, 2020). Además de esto, el año 2019 se publica el libro Por el derecho a la locura. La reinvención de la salud mental en América Latina, el cual presenta 10 relatos en primera persona de activistas latinoamericanos, escritos en narrativa y formato libre (Cea, 2018).

Estas iniciativas buscan tensionar la producción académica sobre discapacidad, a través de la producción literaria situada desde la discapacidad, relevando esta primera voz y la visibilización como una estrategia enmarcada en las bases del conocimiento situado, desafiando la objetividad, la neutralidad, la literatura en formato académico y el método científico en la generación de conocimiento para la transformación social.

\section{Conclusiones}

A través del presente trabajo se ha intentado relacionar las bases del feminismo posestructuralista con algunos activismos de las personas con discapacidad. Hemos identificado que este feminismo, que ha sido influenciado por el posestructuralismo europeo, presenta conceptos, enfoques y teorías que han sido de especial interés para los movimientos contemporáneos de personas con discapacidad alrededor del mundo. En menor medida, el feminismo posestructuralista se ha vinculado con los disability studies y, como se ha demostrado en este análisis, presenta algunas discrepancias que hacen ver a la teoría crip como un nuevo modelo comprensivo de la discapacidad en reemplazo del modelo social (Kafer, 2013; Zerega et al., 2020). Al respecto, Alison Kafer plantea:

"Según Sandahl y McRuer, los estudios sobre la discapacidad y la teoría crip difieren en su orientación y objetivo: la teoría crip es más contestataria que los estudios sobre la discapacidad, y está más dispuesta a explorar los posi- 
bles riesgos y exclusiones de las políticas de identidad, al tiempo que reconoce, "quizá paradójicamente", "el papel generador que la identidad ha desempeñado en el movimiento por los derechos de los discapacitados" [traducción propia] (2013, p. 15).

Estos elementos inspiradores para la discapacidad son variados y numerosos, y podemos resumirlos en dos aspectos. El primero de ellos es fenomenológico, en tanto presenta un enfoque crítico y transgresor sobre el concepto de cuerpo, y el segundo es epistemológico, pues ha destacado la voz y el conocimiento situado, presentando a la experiencia encarnada como un elemento esencial para la construcción de un saber propio. Ambos aspectos desde una estructura antipatriarcal y anticapitalista.

Todos los activismos aquí revisados se sitúan desde la posición de la resistencia, pues todos ellos reconocen las opresiones y las fallas de las políticas sociales enmarcadas en una epistemología hegemónica, y han decidido conscientemente presentar una propuesta alternativa de práctica emancipadora, sustentada en saberes y conocimientos propios que le dan forma y subsistencia.

El movimiento de personas con discapacidad se ha renovado y liberado a través de la influencia del feminismo posestructuralista, y entre ambos han construido espacios de alianza y retroalimentación que les permiten mantener epistemologías flexibles y contextualizadas. Esta liberación es posible de observar a través de aspectos como el orgullo de la discapacidad, los actos performativos de la teoría crip y la pospornografía. Estos sujetos fronterizos, marginados y fetichizados han reclamado y tomado su lugar en la sociedad, alzando sus cuerpos "impropios" en pos de una celebración de la diversidad. Esto no se ha realizado desde una visión caritativa y lastimosa de exhibición de la normalidad a la que estamos acostumbrados/as a través de la institucionalidad, por ejemplo, con la campaña Teletón, sino en el marco de una manifestación de un cuerpo insurrecto que cuestiona el poder biopolítico y lo transforma en poder colectivo.

Aun así, es importante reconocer que no todos los movimientos de personas con discapacidad que han visibilizados temas que son comunes en el feminismo, como la sexualidad, lo hacen desde una perspectiva posestructuralista. En estos otros enfoques reconocemos las posturas de otros feminismos, como el de la igualdad, sobre el reconocimiento de la altísima violencia sexual de las que son víctimas las mujeres con discapacidad en comparación a los hombres (Alcántara et al., 2019) o la prostitución y fetichización de las mujeres con discapacidad (Jeffreys, 2020). Estos planteamientos son ciertamente importantes y, si bien son planteados desde otros tipos de feminismos, su relevancia desafía los análisis posestructuralistas del feminismo en la discapacidad.

El cuestionamiento a la normatividad que ha hecho el feminismo posestructuralista ha contribuido a reforzar la idea del capacitismo como una consecuencia tanto del capitalismo como del patriarcado. A partir de ello, estos colectivos y prácticas colectivas han sido capaces de reconocer las limitaciones y ausencias en la sociedad donde esos cuerpos se desenvuelven, reclamando no solo espacios de atención sanitaria, de rehabilitación o de inclusión educativa/laboral, sino también espacios de participación ciudadana, coconstrucción social y la creación de proyectos autónomos de re-existencias. Aun así, la condición precaria del sujeto con discapacidad en Latinoamérica (Maldonado, 2021) plantea enormes desafíos en cómo el feminismo posestructuralista puede dialogar con el modelo social de la discapacidad o incluso el modelo biopsicosocial, los que resultan favorables para muchas mujeres con discapacidad en situación de precariedad en Iberoamérica (Verdugo, 2003; Ferrante, 2014) y también en países anglosajones (Catapano y Garland-Thomson, 2019; Ryan, 2020), a pesar de sustentarse sobre filosofías de justicia liberal, poniendo en el centro los derechos sociales, tales como la atención sanitaria, la accesibilidad urbana, el acceso a educa- 
ción y empleo y las redes de cuidado, los que muchos colectivos de mujeres con discapacidad defienden. Estas dificultades dialógicas no son nada nuevas, ya desde hace décadas las han planteado diversos teóricos en las discusiones sobre reconocimiento versus redistribución y que dialogaron también las feministas Butler y Fraser (2017) con gran complejidad. Ciertamente este debate no está resuelto, y los ejemplos aquí tratados contribuyen a aclarar la posición del feminismo posestructuralista en esta conversación. Es posible que la complejidad de las sociedades patriarcales actuales requiera una combinación entre los feminismos poestructuralistas con aquellos anticapitalistas para lograr coaliciones lo suficientemente fuertes como para alcanzar la justicia para las personas con discapacidad.

Adicionalmente, la aparición de lo crip como una teoría inspirada en lo queer ha hecho que los investigadores estén actualmente poniendo atención a la repetición de las posibles problemáticas que ha enfrentado la teoría y movimiento queer al levantarse inicialmente sin una crítica profunda al capitalismo y desarrollarse en algunas ocasiones en diálogo con enfoques liberales. Esto lo ha planteado el propio McRuer (2021), pero también lo han hecho otras perspectivas analíticas sobre lo queer actual y futuro, tales como la de Muñoz (2020), las que contribuyen a problematizar este aspecto y desafían la construcción de lo queer y la lucha por lo anti-normativo. Es fundamental para los activismos de la discapacidad que se desarrollan sobre los feminismos poestructuralistas estar atentos a esta discusión y encontrar vías que hagan posible la emancipación del movimiento de la discapacidad desde perspectivas en diálogo con la realidad cambiante y compleja de la sociedad actual.

Como se ha visto a lo largo de este artículo, la mayoría de las experiencias tanto teóricas como prácticas se sitúan en territorios anglosajones y europeos, sin embargo, han emergido algunas experiencias latinoamericanas y chilenas, que aquí se han señalado. Esta comparativa nos ayuda a una mejor interpretación de las prácticas activistas. Aun así, el camino para los movimientos de personas con discapacidad en Latinoamérica en la línea de los feminismos posestructuralistas es largo y probablemente presentará obstáculos ligados a lo instalado que está el capitalismo y el patriarcado, y a las políticas de redistribución que han primado en nuestros estados-nación para la población de personas con discapacidad. En este sentido, y reconociendo las tensiones que existen entre los feminismos posestructuralistas con los decoloniales, latinoamericanos e indígenas, es probable que los colectivos de nuestra América que ya están siendo influenciados por estos enfoques aquí revisados encuentren formas propias de converger, reconociendo las enormes contribuciones que el feminismo posestructuralista ha tenido en los movimientos de personas con discapacidad, pero al mismo tiempo siendo conscientes de las epistemologías feministas propias que han emergido de Latinoamérica y que podrían generar un diálogo de interés en pos de estos movimientos. De todas formas, serán las prácticas de resistencia de los colectivos de las personas con discapacidad latinoamericanos las que hagan dialogar a la teoría, y no al revés. 
Referencias bibliográficas

10 Porn Film Festival Berlin (2015). 10 Porn Film Festival Berlin. 21-25.10.2015 Catalogue. https://pornfilmfestivalberlin.de/archive/PFFB_2015_catalogue.pdf.

Águila, L. (2007). El concepto de discapacidad y su importancia filosófica. Investigación sobre un aspecto fundamental de la condición humana [tesis para optar al Grado de Licenciado en Filosofía]. Pontifica Universidad Católica del Perú.

Alcántara, P. et al. (2019). Se acabó el silencio. Feminismo: cuidado, salud, autonomía. La Moderna.

Alcoff, L. (1988). Cultural feminism versus post-structuralism: The identity crisis in feminist theory. Signs, 13(3), pp. 405-436. https://www.jstor.org/stable/3174166?seq=1.

Arenas, M. (2009). Las mujeres con diversidad funcional (discapacidad) como agentes de transformación social: una perspectiva internacional. Feminismo/s, (13), pp. 49-68. http://dx.doi.org/10.14198/fem.2009.13.04.

Arráez, M. et al. (2006). La Hermenéutica: una actividad interpretativa. Sapiens, 7(2), pp. 171-181. https://www. redalyc.org/pdf/410/41070212.pdf.

Autogestión Libre-Mente (19 de diciembre de 2020). Por sexto año consecutivo posicionamos el Orgullo Loco en Chile, marchando por las calles de la capital Santiaguina, defendiendo la locura, denunciando la violación de nuestros derechos y ejerciendo la expresión de ser Libres de mentes [Imagen adjunta]. Facebook. https://www. facebook.com/permalink.php?story_fbid=2788205584775438\&id=1482554408673902\&_tn__=-R.

Balza, I. (2011). Crítica feminista de la discapacidad: el monstruo como figura de la vulnerabilidad y exclusión. Dilemata, 3(7), pp. 57-76. https://dialnet.unirioja.es/servlet/articulo?codigo=3743414.

Barrera, L. V. et al. (2010). De "El feminismo" a "Los feminismos": propuesta incluyente para grandes luchas. Debate Feminista, 41, pp. 64-74. http://www.jstor.org/stable/42625137.

Barreto, J. (2015). Feminismo y feminismos: consensos y disensos. Tabula Rasa (22), pp. 11-28. http://www.scielo. org.co/pdf/tara/n22/n22a01.pdf.

Barton, L. (2008). Superar las barreras de la discapacidad. 18 años de Disability and Society. Morata.

Blanco, R. (1999). Hacia una escuela para todos y con todos. Boletín del Proyecto Principal de Educación para América Latina y el Caribe (pp. 55-72). UNESCO.

Bogart, K. R. y Nario-Redmond, M. R. (2019). An exploration of disability self-categorization, identity, and pride. En D. S. Dunn (Ed.), Understanding the experience of disability: Perspectives from social and rehabilitation psychology (pp. 252-267). Oxford University Press.

Bravo, P. (14 de diciembre de 2016). Discapacidad y homosexualidad: más que un closet, una cruel prisión heterosocial. Siga Chile. Ciudadanos por la accesibilidad. https://sigachile.udp.cl/2016/12/discapacidad-yhomosexualidad/.

Butler, J. (2007). El género en disputa. El feminismo y la subversión de la identidad. Paidos.

Butler, J. y Fraser, N. (2017). ¿Redistirbución o reconocimiento? Un debate entre marxismo y feminismo. Traficantes de sueños.

Campbell, F. K. (2001). Inciting legal fictions: Disability's date with ontology and the ableist body of the law. Griffith Law Review, (10), pp. 42-62. https://research-repository.griffith.edu.au/handle/10072/3714. 
Cano, M. (2017). Políticas feministas no identitarias. La agencia desde la deconstrucción y la imperceptibilidad. Astrolabio. Revista internacional de filosofía, (19), pp. 45-55.

Cárcamo, H. (2005). Hermenéutica y análisis cualitativo. Cinta moebio, (23), pp. 204-216. https://revistaderechoeconomico.uchile.cl/index.php/CDM/article/view/26081/27386.

Catapano, P. y Garland-Thomson, R. (2019). About us: Essays from the disability series of the New York Times. Liveright.

Cea, J. (2018). Por el derecho a la locura. La reinvención de la salud mental en América Latina. Proyección.

Centeno, A. y de la Morena, R. (Dirs). (2015). Yes, We Fuck! [Documental]. https://www.yeswefuck.org/.

Colectivo AsperGirls Chile [@aspergirlschile]. (3 de Agosto de 2020). Publicaciones [Perfil de Instagram]. Instagram. https://www.instagram.com/aspergirlschile.

Cruz, M. et al. (2012). Conocimiento situado y el problema de la subjetividad del investigador/a. Cinta de moebio, (45), pp. 253 -274. http://dx.doi.org/10.4067/S0717-554X2012000300005.

Cubillos, J. (2015). La importancia de la interseccionalidad para la investigación feminista. Oxímora. Revista internacional de ética y política, (7), pp. 119-137. https://revistes.ub.edu/index.php/oximora/issue/view/1274.

Davis, L. J. (2017). The Disability studies reader. $5^{\mathrm{a}}$ ed. Routledge.

Disability Pride Parade Association (2021). Parade Mission. The 19th Annual Disability Pride Parade Association. https://www.disabilityprideparade.org/parade-mission.html.

Doering, L. (1992). Power and knowledge in nursing: A feminist poststructuralist view. Advances in Nursing Science, 14(4), pp. 24-33. https://doi.org/10.1097/00012272-199206000-00005.

Egaña, L. (2017). Postporno. En R. Platero Méndez et al. (Eds.), Barbarismos queer y otras esdrújulas (pp. 365374). Bellaterra. https://www.academia.edu/35995094/_Postporno_en_BARBARISMOS_QUEER.

Ellies, C. (18 de diciembre de 2016). Paulina Bravo, Odisex: "Las mujeres con discapacidad vivimos en una especie de tubo de ensayo de la sociedad, todo lo que se haga con nosotras parece legítimo". Observatorio Género y Equidad: http://oge.cl/paulina-bravo-odisex-mujeres-con-discapacidad/.

Ferrante, C. (2014). Usos, posibilidades y dificultades del modelo social de la discapacidad. Revista Inclusiones, 1(3), pp. 31-55. http://riberdis.cedd.net/handle/11181/4478.

Ferreira, M. (2008). Una aproximación sociológica a la discapacidad desde el modelo social: apuntes caracteriológicos. Revista Española de Investigaciones Sociológicas (Reis), (124), pp. 141-174. http://www.reis.cis.es/ REIS/PDF/REIS_124_051222873458779.pdf

Fonseca, C. y Quintero, M. (2009). La teoría queer: la de-construcción de las sexualidades periféricas. Sociológica, 24(69), pp. 43-60. http://www.scielo.org.mx/pdf/soc/v24n69/v24n69a3.pdf.

Fuentes, X. et al. (2021). Revisión teórica del modelo social de discapacidad. Propósitos y Representaciones, 9 (SPE1), e898. http://dx.doi.org/10.20511/pyr2021.v9nSPE1.898.

Gadamer, H. G. (1991). Verdad y método (vol. 1). Ediciones Sígueme.

Gallego, J. (7 de mayo de 2015). Yes, We Fuck. La Marea. https://www.lamarea.com/2015/05/07/yes-we-fuck/. 
García, J. (2012). Cuerpos impuros: Butler, Haraway, Preciado. Thémata. Revista de Filosofía, (46), pp. 377-384. https://dialnet.unirioja.es/servlet/articulo?codigo=4683794.

García-Santesmases, A. (2017). Cuerpos (im)pertinentes. Un análisis queer-crip de las posibilidades de subversión desde la diversidad funcional [tesis para optar al título de Doctora en Sociología]. Universitat de Barcelona. http://diposit.ub.edu/dspace/bitstream/2445/109589/4/AGSF_TESIS.pdf.

García-Santesmases, A. y Arenas, M. (2017). Playing crip: the politics of disabled artists' performances in Spain. Research in drama education: The journal of applied theatre and performance, 22(3), pp. 345-351. http://dx.doi. org/10.1080/13569783.2017.1327804.

Garland-Thomson, R.(2005). Feminist disabilitystudies.Signs, 30(2), pp.1557-1587.https://doi.org/10.1086/423352.

Garland-Thomson, R. (2017). Integrating disability, transforming feminist theory. En L. J. Davis (Ed.), The Disability Studies Reader. $5^{\mathrm{a}}$ ed. (pp. 360-380). Routledge.

Guzmán-Cáceres, M. (2015). Multiplicar los sujetos, encarnar los Conocimientos Plausibilidad de la epistemología social posmoderna de Donna Haraway. Boletín Científico Sapiens Research, 5(22), pp. 39-44. https://dialnet. unirioja.es/servlet/articulo?codigo=6181582.

Haraway, D. (1991). Ciencia, cyborgs y mujeres. La reinvención de la naturaleza. Ediciones Cátedra-Universitat de Valencia.

Hopson, J. (2019). Disability as Culture. Multicultural Education, 27(1), pp. 22-24. https://eric.ed.gov/?id=EJ1250140.

Jeffreys, S. (2020). Ensayos sobre políticas sexuales. Labrys Editorial.

Kafer, A. (2013). Feminist, queer, crip. Indiana University Press.

Linton, S. (1998). Disability studies/not disability. Disability \& Society, 13(4), pp. 525-540. https://doi. org/10.1080/09687599826588.

López-Radrigán, C. (2020). Estudios feministas de discapacidad en Iberoamérica: una aproximación al estado de la discusión. Nómadas, (52), pp. 97-113. https://doi.org/10.30578/nomadas.n52a6.

Maldonado, J. (2020). Sentir la discapacidad en tiempos neoliberales: optimismo cruel y fracaso. Nómadas, (52), pp. 45-59. https://doi.org/10.30578/nomadas.n52a3.

Maldonado, J. (2021). La condición precaria del sujeto con discapacidad. En P. M. Danel, et al. (Comps.), ¿Quién es el sujeto de la discapacidad? Exploraciones, configuraciones y potencialidades (pp. 101-126). CLACSO.

McRuer, R. (2018). Crip times: Disability, globalization and resistance. NYU Press.

McRuer, R. (2021). Teoría crip. Signos culturales de lo queer y de la discapacidad. Kaótica Libros.

Mareño, M. (2021). Una aproximación a la teoría crip: la resistencia a la obligatoriedad del cuerpo normativo. Argumentos. Revista de crítica social, (24), pp. 377-429. https://publicaciones.sociales.uba.ar/index.php/argumentos/article/view/6987/5840.

Mello, A. G. (2014). Gênero, deficiência, cuidado e capacitismo: Uma análise antropológica de experiências, narrativas e observações sobre violências contra mulheres com deficiência [tesis para optar al Grado de Mestra em Antropologia Social]. Universidade Federal de Santa Catarina. https://repositorio.ufsc.br/handle/123456789/182556.

Miranda, B. (2020). De la norma al nombre: el arte y la invitación a reinventar el acivismo en la "discapacidad". En S. Hartwig (Ed.), Inclusión, integración, diferenciación. La diversidad funcional en la literatura, el cine y las artes 
escénicas (pp. 219-232). Peter Lang.

Morris, J. (1996). Encuentros con desconocidas. Narcea.

Moscoso, M. y Arnau, S. (2016). Lo queer y lo crip, como formas de re-apropiación de la dignidad disidente. Una conversación con Robert McRuer. Dilemata, 8(20), pp. 137-144. https://dialnet.unirioja.es/descarga/articulo/5329396.pdf.

Muñoz, J. (2020). Utopía queer. El entonces y allí de la futuridad antinormativa. Caja Negra.

Palacios, A. (2008). El modelo social de discapacidad: orígenes, caracterización y plasmación en la Convención internacional sobre los derechos de las personas con discapacidad. CERMI y Ediciones Cinca.

Peralta, J. (2017). Usina posporno. Disidencia sexual, arte y autogestión en la pospornografía. MORA, (23), pp. 231-234. http://revistascientificas.filo.uba.ar/index.php/mora/article/download/5216/4707.

Pérez, M. y Chhabra, G. (2019). Modelos teóricos de discapacidad. Un seguimiento del desarrollo histórico del concepto de discapacidad en las últimas cinco décadas. Revista Española de Discapacidad, 7(1), pp. 7-27. https://doi.org/10.5569/2340-5104.07.01.01.

Pfeiffer, D. (2002). The philosophical foundations of disability studies. Disability Studies Quarterly, 22(2), pp. 3-23. http://dx.doi.org/10.18061/dsq.v22i2.341.

Piazzini, C. (2014). Conocimientos situados y pensamientos fronterizos: una relectura desde la universidad. Geopolítica(s), 5, pp. 11-33. http://dx.doi.org/10.5209/rev_GEOP.2014.v5.n1.47553.

Pino, J. y Rodríguez, P. (2017). ¿Vivir para trabajar?: activismo, mujeres y discapacidad en Chile. Intersticios. Revista sociológica de pensamiento crítico, 11(2), pp. 185-198. http://www.intersticios.es/article/view/17704.

Preciado, P. B. (2015). Activismo posporno. Parole de queer: columna de opinión. http://paroledequeer.blogspot. com/2015/04/activismo-posporno-por-paul-b-preciado.html.

Proyecto Kahlo (2014). Mi cuerpo no es normativo, y el tuyo tampoco. Proyecto Kahlo. La revolución comienza en tu interior. https://www. proyecto-kahlo.com/.

Rifa, M. (2003). Michel Foucault y el giro postestructuralista crítico feminista en la investigación educativa. Educación y pedagogía, 15(37), pp. 69-83. https://dialnet.unirioja.es/servlet/articulo?codigo=2556803.

Rodríguez, I. (2013). Representaciones disidentes de las sexualidades. Revista Venezolana de Estudios de la Mujer, 18(41), pp. 257-268. http://saber.ucv.ve/ojs/index.php/rev_vem/article/view/6076/5865.

Ryan, F. (2020). Crippled. Austerity and the demonization of disabled people. Verso.

Scott, J. (1988). Igualdad versus diferencia: los usos de la teoría postestructuralista. Feminist studies, 14(1).

Shakespeare, T. (2017). The social model of disability. En L. J. Davis (Ed.), The Disability Studies Reader (pp. 195203). Routledge.

Smiraglia, R. (2012). Sexualidades de(s)generadas: algunos apuntes sobre el postporno. Imagofagia, (6), pp. 1-22. http://asaeca.org/imagofagia/index.php/imagofagia/article/view/335.

Toboso, M. (2017). Capacitismo. En L. Platero et al. (Eds.), Barbarismos queer y otras esdrújulas (pp. 73-81). Bellaterra.

Torrico, E. (4 de septiembre de 2016). Así son las ONG españolas que facilitan sexo a personas discapacitadas. 
El Confidencial. https://www.elconfidencial.com/sociedad/2016-09-04/sexo-discapacitados-tandem-teamasistencia-sexual_1254701/.

Universidad Internacional de Andalucía (2011). Resumen del seminario impartido por Beatriz Preciado. Universidad Internacional de Andalucía.

Urra, E. (2007). La teoría feminista post-estructuralista y su utilidad en la ciencia de la enfermería. Ciencia y enfermería, 13(2), pp. 9-16. http://dx.doi.org/10.4067/S0717-95532007000200002.

Verdugo, M. A. (2003). La concepción de la discapacidad en los modelos sociales. Mesa Redonda: ¿Qué significa la discapacidad hoy? Cambios conceptuales. https://sid.usal.es/idocs/F8/FDO7103/concepcion_discapacidad.pdf.

Wolbring, G. y Guzmán, P. (2016). Human enhacement through the ableism lens (an e-mail interview made by Francisco Guzmán). Dilemata. Revista Internacional de Éticas Aplicadas, (3), pp. 1-13. https://www.dilemata. net/revista/index.php/dilemata/article/view/31/46.

Wong, A. (2018). Resistance and hope: Essays by disabled people. Disability Visibility Project.

Wong, A. (2020). Disability visibility. Vintage.

Yarza, A. et al. (2019). Estudios críticos en discapacidad. Una polifonía desde América Latina. CLACSO. https:// www.clacso.org/wp-content/uploads/2020/06/GT-Estudios-criticos-discapacidad.pdf.

Zambrini, L. (2014). Diálogos entre el feminismo postestructuralista y la teoría de la interseccionalidad de los géneros. Revista Punto Género, (4), pp. 43-54. https://analesfcfm.uchile.cl/index.php/RPG/article/view/36408/38040.

Zerega, M. M. et al. (2020). Devenir discapacitado: nuevos monstruos, cyborgs y desplazados en el capitalismo contemporáneo. Nómadas, (52), pp. 149-165. http://dx.doi.org/10.30578/nomadas.n52a9.

Zunino, N. (15 de noviembre de 2017). Ellos quieren sexo. La Tercera. https://www.latercera.com/paula/ellosquieren-sexo-2/.

Zurro, J. (29 de marzo de 2015). Libertad, igualdad y sexualidad. El Confidencial. https://www.elconfidencial.com/ cultura/cine/2015-03-29/libertad-igualdad-y-sexualidad_743291/. 